\title{
A Study on Problems and Solutions in Elementary English Online Class
}

\author{
초등 영어 온라인 수업의 문제점과 방안 \\ Hae Kyoung Lee ${ }^{1}$, Bo Mi Kim² \\ ${ }^{1}$ Professor, Gongju National University of Education, Department of English Education, Korea, \\ hklee@gjue.ac.kr \\ ${ }^{2}$ Teacher, The Attached Elementary School of Gongju National University of Education, Korea, \\ bbom-e@hanmail.net
}

Corresponding author: Hae Kyoung Lee

\begin{abstract}
The outbreak of corona virus pandemic posed serious problems not only to health and economics, but also to education systems all over the world. Amid COVID-19, both teachers and students were forced to undergo a radical shift as the use of online technology has no longer become optional to them. Under this circumstance, language teachers may find that their professional identity has been confronted and challenged. This paper aims to examine the problems and solutions of the primary English online class brought about by Covid-19 pandemic. First, the most frequently mentioned reason for the ineffectiveness of primary English online classes is that teachers cannot immediately understand their students' situations and provide the necessary guidance. If appropriate technology is in place, individualized learning can produce effective and the efficient English learning and communicate in various ways. Second, while presenting the need to build an integrated platform as a remote class improvement task, there is a need to ensure diversity and scalability of the content and methods of teaching- learning activities. Third, teachers are expected to continue to offer positive opinions on the continued use of online classes after Covid-19 pandemic, expanding the form of class models that utilize self-directed software using artificial intelligence(AI) or link online and offline.
\end{abstract}

Keywords: Elementary English, Problems and Solutions in Online Class, Individualized Learning, Integrated Platform, Artificial Intelligence

요약: COVID-19로 인해 전 세계는 건강이나 경제적인 문제뿐만 아니라 이로 인해 교사와 학생에게 온라인 기술을 활용한 수업으로의 전환이 이제는 더 이상 교육현장에서 선택이 아닌 필수가 된 것은 주지의 사실이다. 본 연구는 코로나 19 로 인해 시작된 초등 영어 온라인 수업을 바탕으로 온라인 수업의 문제점과 해결 방안을 모색하고 수업에 대한 효과성 인식, 인공지능 활용 영어 수업과 같은 미래지향적인 수업 방향을 제시하고자 하였다. 첫째, 초등영어 온라인 수업이 효과적으로 이루어지기 위해 적절한 첨단 장비와 기술을 갖추어 학습자에게 개별화된 학습으로 효과적이고 효율적 영어학습이 제공되어야 하고, 둘째, 온라인 수업을 가능하게 하는 다양한 통합 플랫폼 구축의 활성화와 교수학습 활동의 다양성을 확보함과 동시에 온라인 수업 역량 강화를 위한 장.단기적 연수프로그램을 개발해야 하며, 셋째, 미래교육의 방향으로 인공지능(AI)을 활용한

Received: September 8, 2021; $1^{\text {st }}$ Review Result: October 22, 2021; $2^{\text {nd }}$ Review Result: December 12, 2021 Accepted: January 29, 2022 
자기주도력 신장을 위한 맞춤형 소프트웨어를 통해 온·오프라인에 연계한 수업 형태를 설계하고 가속화 시켜야 한다.

핵심어: 초등영어, 온라인 수업, 개별화 학습, 통합 플랫폼, 인공지능

\section{1. 서론}

코로나19로 인해 2020년 유례없는 온라인 개학과 동시에 일명 언택트(Untact)가 생활 양식으로 자리잡았다. 비대면으로의 전환은 교육계에도 큰 변화를 가져왔다. 집단생활을 기본으로 하는 기존의 전통적인 등교 수업 방식은 전염병에 너무나 취약했다. 학생들의 안전이 최우선이라는 사회적 합의에 따라 여러 차례 휴업 연장이 반복되었고, 결국 사상 초유의 840 만 학생의 온라인 개학 사태를 맞이하게 되었다. 교육계에서도 원격수업과 등교 수업을 병행하며 비대면 교육 환경 정착을 위한 노력을 올 한해 진행하였다. 초등학교의 경우, 공교육이 시작되는 단계로 초등학생 시기에 형성된 온라인 수업에 대한 심리적, 학습적 태도와 물리적 환경은, 이어지는 중·고등학교 교육에도 영향을 미친다. 특별히 영어과목에 있어서의 온라인 활용은 많은 효과를 가져온다고 한다.(김정렬, 2008)[1]. 김희진(2018)의 연구에 의하면 스마트 러닝의 높은 실재감을 기반으로 한 상호작용이 영어 학습의 몰입이나 만족도에 유의미한 영향을 보였다[2]. 또한 이유화(2020)는 온라인 학습과 오프라인 학습을 결합한 수업이 학습자들의 영어 독해와 말하기 능력 향상에 효과적이었으며, 만족도에 유의미한 영향을 미침을 밝혔다[3]. 이렇듯 온라인 영어 학습과 관련된 선행 연구와 시도가 많은 만큼 온라인 수업 체계화에 영어 과목이 선두 과목이 될 수 있다는 점을 시사한다.

이에 본 연구의 목적은 첫째, 초등영어 온라인 수업의 문제점을 교사 측면, 학부모 측면, 그리고 학생 측면에서 살펴보고 둘째, 이를 극복하기 위한 방안을 모색하여 미래 온라인 수업의 방향을 제시하고자 하는 것이다.

\section{2. 이론적 배경}

\section{1 온라인 수업}

현행법상 온라인 수업에 대한 정의가 규정되어 있지 않은 만큼 이에 대한 학문적 논의가 다양하다. 해외에서는 Hiltz(1990)에 의해 '가상 수업'이라는 단어가 처음 만들어진다. '가상 수업'이란, 컴퓨터 통신을 매개로 하여 토론, 실험, 강의 등 교실에서 이루어지는 수업 형태를 전자화하여 이루어진 수업 형태를 의미한다. 미국 교육부는 온라인 수업에 두 가지 의미를 포함하였는데, 면대면 학습을 대체하는 경우와 면대면 교육과 온라인 수업을 혼합하여 사용하는 블랜디드 러닝이 그 내용이다[4].

\section{2 온라인 수업 모델}

Romiszowski와 Mason(2004)은 온라인 수업을 사이버형, 통합형, 보조형 세 가지 형태로 나눈다. 첫째, 사이버형은 모든 교육의 과정이 사이버 공간에서 이루어지는 형태로, 사이버대학에서 사용하고 있는 유형이다. 이때 학습의 과정뿐 아니라 교사와 학생의 
의사소통 또한 모두 정보 매체를 통해 이루어진다. 둘째, 통합형은 온라인과 면대면을 절충하여 교수 학습의 과정을 이루는 수업 형태이다. 셋째, 보조형은 기본적인 학습 활동은 면대면으로 이루어지고, 온라인 수업은 보조 도구로 사용한다[5].

\section{3 미래교육과 AI}

4차 산업혁명 시대를 선언한 다보스 경제 포럼(WEF, 2016) 이후, 국제사회는 새로운 시대 패러다임에 부합하는 방향으로 개혁을 이끌고 있다. 특히, 변화되는 시대의 핵심 가치를 초연결, 초지능 및 초융합에 두고, 이러한 가치를 실현할 수 있는 구현기술(Enabling Technology)인 5G, AI, Block Chain, BigData Analytics, VR/AR/MR, CyberPhysical System 등에 주목하게 되었고, 이들 기술 표준의 선점에 세계 각국의 경쟁이 치열한 상황이다. 구현기술 중에서, 특히, 인공지능(Artificial Intelligence)이 가장 핵심으로 부각되고 있다[6].

\section{3. 연구 방법}

\section{1 연구 대상}

본 연구는 공동 연구원이 소속되어 있는 $\mathrm{C}$ 지역의 $\mathrm{A}$ 초등학교 3 학년 남학생 12 명과 여학생 8명, 그리고 5학년 남학생 48명과 여학생 36명을 대상으로 진행되었으며 2020년 4 월부터 시작하여 약 10 개월간의 초등 영어 온라인 수업 실시를 바탕으로 진행하였고, 이후 인공지능 활용 영어 수업에 대한 연구는 2021년 3월부터 7월까지 약 5개월간 영어 전담 교사를 대상으로 진행하였다.

\section{2 연구 방법}

본 연구는 온라인 영어 수업에 참여한 초등학생들을 대상으로 매주 영어 수업 경험에 대한 관찰, 과제 수행도, 면담 등을 통해 이루어졌으며, 본 연구에서 활용된 설문지는 실태 분석과 만족도, 개선 및 요구사항 영역으로 나누어 13 개의 문항으로 구성하였고 온라인 수업에 참여한 초등 영어 교사들의 실제 이야기를 심층면담 및 녹음하였다.

\section{4. 연구 결과}

\section{1 초등 영어 온라인 수업의 문제점}

\subsection{1 교사 측면}

\subsubsection{1 교사의 온라인 수업 역량 부족의 어려움}

교사들은 온라인 수업을 개발하고 운영하는 과정에 대해 어렵다고 생각하였다. 온라인 영어 수업을 직접 개발하고 운영해야 하는 경험이 교사들에게는 대다수 처음이었기 때문에 온라인 수업에 역량을 발휘할 수 있는 부분이 부족했던 것이다. 따라서 짧은 시간 안에 소프트웨어, 플랫폼 등과 관련한 내용과 기술적인 것을 학습하고 이것을 어떻게 교육적으로 풀어낼 것인가를 고민하는 과정이 필요했다. 


\subsubsection{2 학교의 IT 인프라와 기술 지원체계 부족의 어려움}

학교에서 제공하는 온라인 수업에 관한 인프라의 부족을 문제점으로 인식하였다. 국내 초중등학교는 과거에 온라인 수업을 거의 진행하지 않았으므로 관련 인프라를 체계적으로 갖추기에는 어려움이 있었을 것이고 IT 전문성을 확보한 인력 등의 지원 시스템도 거의 찾아볼 수 없었다. 특히 외국어인 영어교과는 학교별 전문 인력 확보 등 기술 지원 체계에 있어 더욱 부족한 형편이다.

\subsection{2 학부모 측면}

학부모 입장에서는 유튜브에 접속하는 것의 어려움, 피드백의 부족, 부모가 직접 학습을 점검하는 것의 어려움, 교사의 콘텐츠 제작 노력 부족, 영상 시청 시간에 대한 자녀의 학습태도 확인의 어려움, 교사의 편차가 심하다는 점, 동영상 만으로는 수업이 매우 부족하다는 점등을 불만의 요소로 제기하였다.

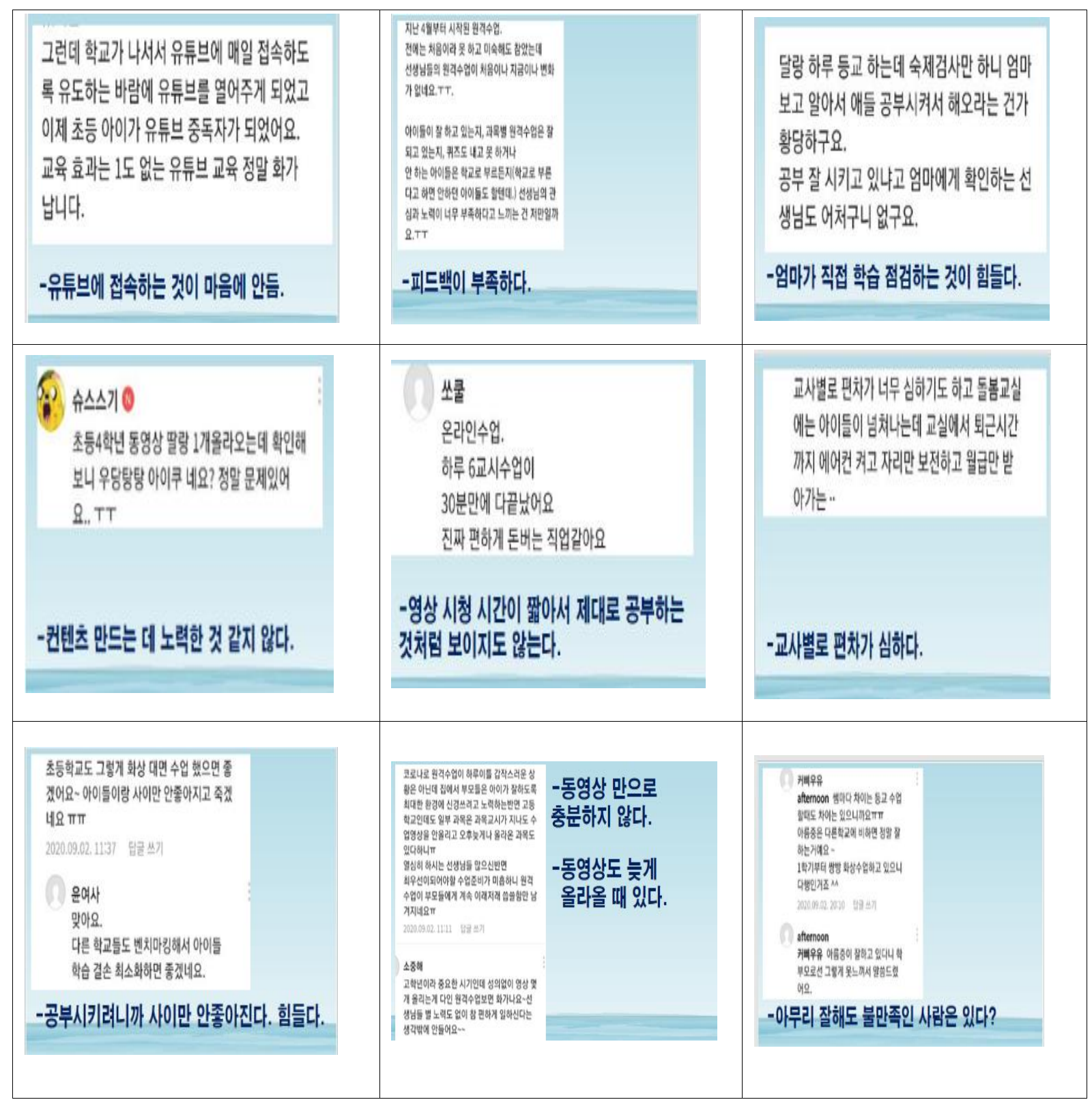

[그림 1] 초등영어 온라인 수업의 학부모 측면 문제점

[Fig. 1] Parental Problems in Elementary English Online Classes 


\subsection{3 학생 측면}

\subsubsection{1 온라인 출결 관리 등 학습 지원의 어려움}

초등영어교육의 목표는 기초적인 영어를 이해하고 표현하는 능력을 기르는 것인데 기초 학습 능력 자체가 부족한 학생은 온라인 영어 수업에서 참여하지 않음으로써 수업이 지속될수록 타교과목 보다 학습 결손과 격차가 더욱 심화되는 현상을 나타냈다. 실제로 교사들은 온라인 영어 수업에 학생들을 출석시키기 위해 아침마다 전화와 문자 등 많은 노력을 해야 했다. 그리고 학습 지원에 어려움이 있는 학생들 중에는 가정환경이 뒷받침되지 못하는 취약 계층의 학생들이 특히 많아 이들에 대한 지원이 더욱 절실한 것으로 인식되었다.

\subsubsection{2 취약계층에 대한 IT 인프라 지원의 어려움}

온라인 수업 진행의 문제점으로는 저소득층 등 취약계층 학생들이 온라인 수업에 필요한 인프라를 갖추지 못해 원활한 영어 수업 진행이 어려웠다는 점이다. 즉, 온라인 수업을 원활하게 수강하기 위해 갖추어야 할 인프라는 학교에서뿐만 아니라 학생에게도 필수적인 것으로 보이며 학생 가정에 제대로 된 인프라를 갖출 수 있도록 지원하지 못한다면 온라인 수업은 불가능하다.

\section{2 초등 영어 온라인 수업 문제에 대한 해결방안}

\subsection{1 교사 측면}

교사의 역량을 키워줄 수 있는 효과적이고, 체계적인 연수 프로그램의 필요성을 가장 많이 언급하였다. 특히 연수 프로그램이 초등영어 교과와 학교의 특성을 반영하여 실질적인 내용으로 구성되어야 함을 강조하였다. 또한 교사 간의 수업 사례와 방법론 공유 등이 적극적으로 이루어지기를 희망하였다. 교사 커뮤니티의 지식과 경험 공유가 보다 체계화되고 활성화될 필요가 있다. 강의 개발을 위한 인프라 구비 역시, 체계적이고 종합적인 계획을 세워서 이루어져야 하며, 영어 교과 및 수업의 특성을 반영하여 인프라가 구비되어야 한다는 점이 강조되었다. 즉, 영어지도에 필요한 다양한 소프트웨어와 디바이스 중 수업에 적합한 것을 선별해 내고 적절한 예산을 투입하여 적소에 배치하는 의사결정이 효율적으로 이루어질 필요가 있다.

\subsection{2 학부모 측면}

학부모의 입장에서는 자녀가 유튜브에 매일같이 접속해서 학습을 하는지, 학습과 관련 없는 영상을 보게 되는지에 대해 의심이 생기고 불안해할 수 있다. 이러한 문제를 해결하기 위해서는 교사가 직접 영상을 제작하고, 제작 시 용량을 최소한으로 줄일 수 있도록 노력하는 수밖에 없다. 다만 이 경우, 영상의 해상도가 떨어지는 것과 같은 부작용은 감수해야 할 것이다. 학부모가 직접 영어학습을 점검하는 것의 어려움은 특히 저학년의 자녀를 둔 학부모에게서 더욱 많이 볼 수 있다. 학생들은 원격 수업에 완전히 적응했다고 볼 수 없다. 이를 도와주고 지켜봐야 하는 학부모들의 심리적, 물리적 부담은 상당하며 특히 영어 교과는 외국어에 대한 불안도 많아 교사는 적절한 양의 과제를 제시하여 학생이 스스로 과제에 몰입하는 시간을 늘려주고 원격학습에 접근하는 방법도 가급적이면 쉽도록 세심한 신경을 쓸 필요가 있다. 실제 수업은 교사와 학생 간의 상호작용을 포함한 활동들로 구성되어 있지만 영상 수업은 교사의 일방향적 메시지 
중심으로 구성되어 있기 때문에 실제 영어 수업 시간과 제작에 의한 영상 수업의 길이는 차이가 나고 또한 영상 안에는 학생들의 활동 시간이 포함되기가 어렵다. 그럼에도 불구하고 학부모의 이러한 오해를 줄이려면, 영상 속에서 과제를 제시하고 일정 시간 기다려준다거나, 발문하고 시간을 두어 학생이 마치 교사와 실시간으로 상호작용하는 것처럼 유도하는 식으로 영상을 제작하는 것이 바람직하다.

\subsection{3 학생 측면}

학업에 어려움을 겪는 학생들에 대해 오프라인으로 만나 개별(보충)지도를 하는 방식을 제시하였다. 일부 학생들은 교사의 출결 확인 후 수업 동영상을 켜 놓은채 수업 외의 다른 일을 하는 경우가 많아 학부모 입장에서는 온라인 수업을 하는 교사에 대해서 부정적으로 인식한다고 볼 수 있다. 미래에는 모든 영어학습자들이 온라인 학습에 적절한 IT 인프라를 준비하여 불편함 없이 공부할 수 있도록 체계적인 정비가 확보되어야 한다고 하였다. 특별히 스스로 문제를 해결하기 어려운 저학생 학생이나 정보화에 대한 능력이 떨어지는 학생은 IT 장비를 가지로 네트워크를 연결하여 프로그램에 참여하는 등의 여러가지 학습상황을 스스로 하기에 많은 어려움이 있으므로 보다 적극적이고 섬세한 지원이 요구된다.

\section{3 초등 영어 미래 수업의 방향}

지금까지의 온라인 수업 경험을 바탕으로 보다 미래 지향적인 개선 방향과 향후 활용 가능성에 대해 다음과 같이 제시하고자 한다.

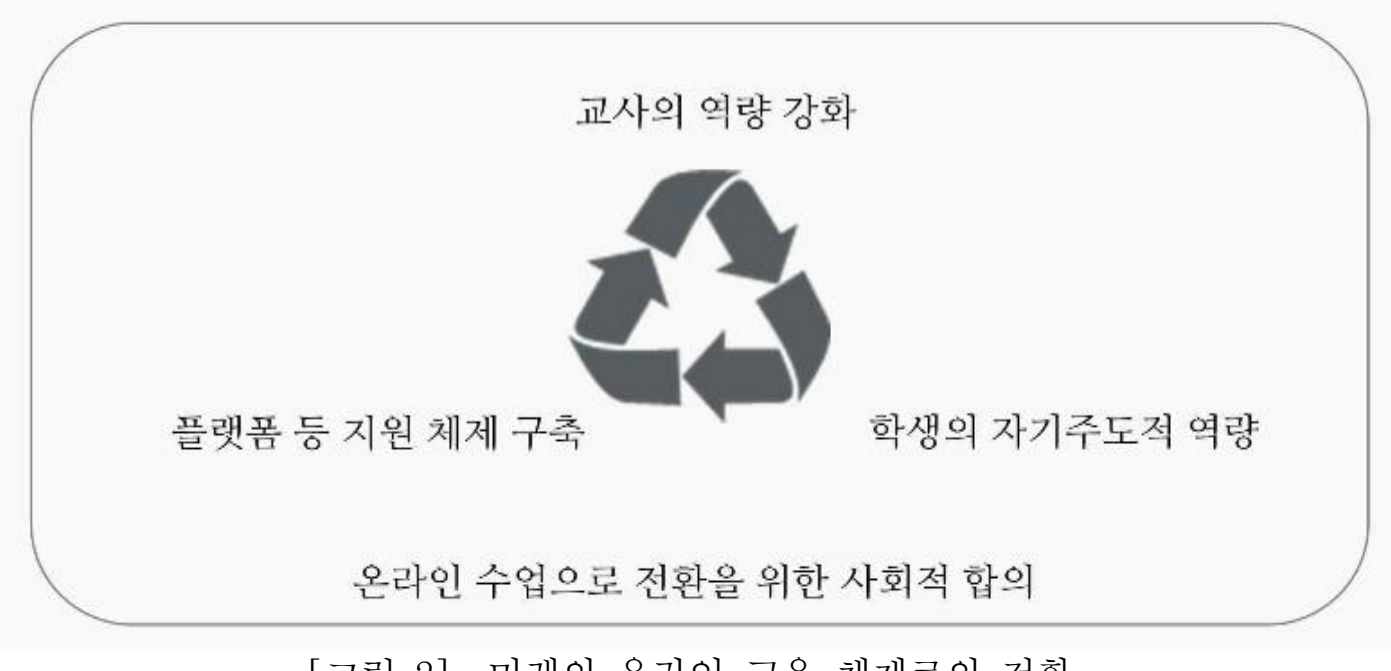

[그림 2] 미래의 온라인 교육 체제로의 전환

[Fig.2] A Reversion to the Future of Online Education System

\subsection{1 디지털 리터러시의 개념}

디지털 리터러시의 개념은 다양한 디지털 매체를 활용한 능동적인 참여와 커뮤니케이션 할 수 있는 능력(허경아, 2011)으로 디지털 사회에서 구성원으로서 살아가기 위해 요구되는 필수 역량이라고 정의할 수 있다[7]. 이러한 디지털 리터러시 능력은 
교사들 사이에서도 그 격차가 크게 나타날 수 있다. 특히 중년 이상의 교사들의 심리적 부담감은 매우 높은 상황으로 보였고, 또한 여성 교사에게서 더 부담이 많은 것으로 나타났다. 이와 같이 프로그램이나 플랫폼, 스마트기기와 IT등을 사용하는 데 느끼는 어려움은 교사 개인의 성향에 따라 다르기 때문에 서로 상호 협력하여야 할 것이다.

\subsection{2 학생의 학습능력 향상을 위한 프로그램 개발}

온라인 수업에 있어서의 어려움의 원인으로는 학생들이 학습하고자 하는 바를 집중하여 참여하지 못할 때, 교사가 이를 즉각 파악할 수 없다는 점이다. 따라서 온라인 수업 콘텐츠의 질적 개선과 함께 학생들이 흥미 있게 참여할 수 있는 콘텐츠, 수준별 콘텐츠, 쌍방향 수업과 피드백의 정착 등 학습 격차가 일어나지 않도록 노력해야 할 것이다. 또한 자기주도학습 능력 향상을 위한 다양한 기술과 프로그램들이 개발되어 학생들이 언제 어디서나 스스로 학습할 수 있는 환경이 조성되어야 할 것이다.

\subsection{3 혼합형 수업 모델 적용 확대(블렌디드러닝, 플립러닝을 중심으로)}

블렌디드 러닝이란, 일반적으로 인터넷을 활용한 이러닝과 전통적인 면대면 방식 수업을 혼합한 교육 방식을 일컫는 것으로 혼합형 학습 등으로 불리며(김현정, 나경희, 2014), 가장 대표적으로는 플립러닝이 있다. 플립러닝은 가정에서 온라인 영상을 시청한 후, 오프라인 수업에서 사전 학습에 대한 내용을 활용하여 학습을 진행하는 방식이다. 온라인으로 핵심적인 내용을 수강하고, 교실에 와서는 학습자 중심적인 활동을 하며 의도치 않게 거꾸로 수업을 하게 되었다는 동료 교사가 많다[8]. 현재 상황에서는 불가피하게 적용된 대안적 성격이 강하지만, 지금이 오히려 기회가 되어 앞으로의 미래 교육의 방식과 내용 등을 생각해보고 시도해볼 수 있을 것으로 생각된다.

\subsection{4 인공지능(AI) 활용 교육}

\subsubsection{1 인공지능(AI) 기반 교육 모형}

인공지능 기반 교육의 모형은, 인공지능 기반 사회에서 삶의 모형, 즉 개체 혹은 구성원으로서의 인간이 인공지능 활용 역량을 토대로 삶의 문제를 해결해 나가는 모형을 그대로 영어교육에 대입하여 구성하였다. 인공지능 기반 교육의 모형은 [그림 3]과 같다.

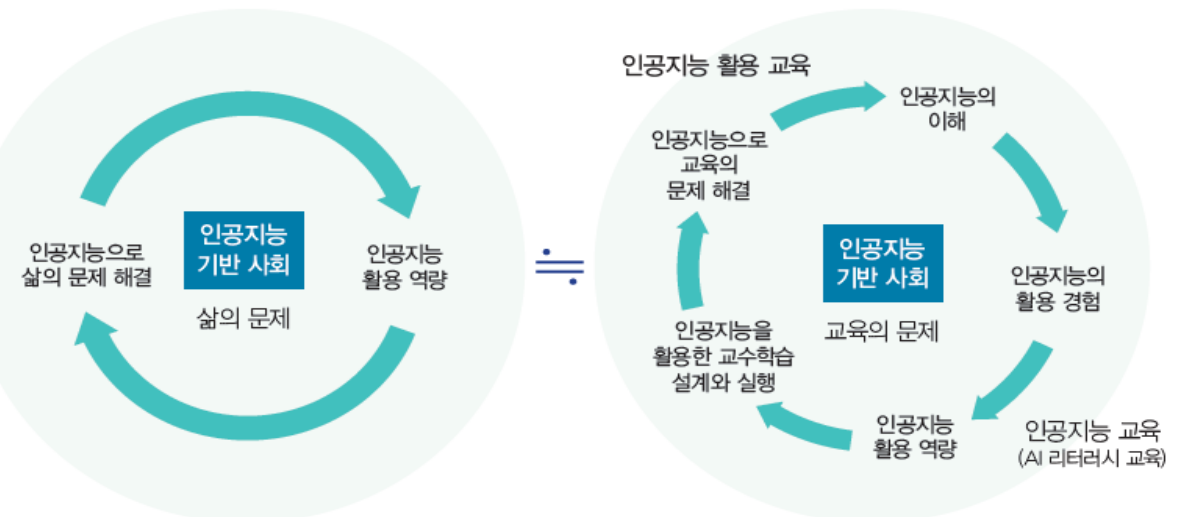

[그림 3] 인공지능 기반 교육의 모형

[Fig. 3] The Model of Education based on Artificial Intelligence 


\subsubsection{2 인공지능(AI) 활용 영어 수업 실천적 경험}

1) 인공지능 번역기(구글 번역기, 파파고를 중심으로)

인공신경망(Artificial Neural Network)을 기반으로 하는 번역 서비스인 구글 번역기나 네이버 파파고 어플과 같은 번역기를 사용하여 학생들에게 평소 영어 단위 수업 시간과 자투리 시간을 활용하여 개별적인 영어 단어 검색 기능과 작문 경험을 주었다. 학생들은 개별 스마트패드를 활용하여 영어 시간에 번역기를 옆에 두고 읽기, 쓰기 활동뿐만 아니라 각자 필요하다고 생각하는 활동에서 자유롭게 번역기를 활용하였다.

2) $\mathrm{AI}$ 펭톡

교육부와 $\mathrm{EBS}$ 가 개발한 인공지능 기반 영어 말하기 연습 시스템인 $\mathrm{AI}$ 펭톡은 초등학생들이 영어를 효과적으로 학습할 수 있도록 듣고 말하는 환경을 풍부하게 제공하여 기초 의사소통 능력 향상을 지원한다. 음성 인식과 자연어 처리 기술을 활용하여 인공지능(AI)과 학생 간 $1: 1$ 대화가 가능한 서비스는 물론 2015 개정 영어 교육과정과 EBS 영어 교육자료(콘텐츠)에서 추출한 단어, 문장, 대화를 연습할 수 있도록 발음 교정 서비스도 제공한다.

3) 인공지능(AI) 활용 수업 만족도 결과

학생들은 구글 번역기나 파파고 어플을 사용하는 영어 활동 시 그렇지 않을 때보다 이해하기 쉬웠다는 반응을 보였다. 번역기를 활용한 학습이 영어의 4기능에서 도움이 되는 영역 순서로는 듣기-읽기-말하기-쓰기 순으로 나타났다. 펭톡을 활용한 영어 수업은 과반수가 넘는 학생이 긍정적으로 답변하였으며 $\mathrm{AI}$ 펭톡 학습 코너중 가장 흥미로운 코너는 토픽월드로 스테이지별로 듣고 문제를 푸는 활동에 성취감을 느꼈을 것이다. 펭톡 활용으로 향상된 영어 학습 영역 순서로는 듣기-말하기-읽기-쓰기 순으로 나타났다. 이는 펭톡 어플이 자기주도적으로 듣고 말할 수 있는 개별학습 지원 시스템임을 시사한다. 구글 번역기를 실행했을 때 원하는 답을 얻었는가에 대한 실행 만족도는 매우 높았으나, 펭톡 어플의 개별 영어 보조학습 지원에 대한 만족도는 보통 수준이었다. 이는 학교에서 정규시간에 사용한 시간이 많지 않았고 가정과 연계하여 지도하였지만 즉각적인 피드백을 주는 데 어려움이 있었음을 나타낸다. 마지막으로 인공지능 활용 수업 전반에 대한 만족도는 매우 높게 나타나 학생들이 인공지능 매체와의 상호 작용에서 만족감을 느끼고 있으며, 콘텐츠 요인의 경우 우선적으로 개선이 이루어져야 함을 나타낸다.

\section{5. 결론 및 제언}

본 연구는 코로나19로 인해 시작된 초등 영어 온라인 수업을 바탕으로 온라인 수업의 문제점과 해결 방안을 모색하고 수업에 대한 효과성 인식, 인공지능 활용 영어 수업과 같은 미래지향적인 수업 방향을 제시하고자 하였다.

첫째, 초등영어교육에 있어서 온라인 수업이 효과적으로 진행되기 어려운 이유 중 많이 언급되는 것은 교사가 학생들의 수업 상태를 즉시 파악하여 지도할 수 없다는 점이고, 특히 여러 가지 환경적으로나 개인적으로 온라인 수업에 참여하기 어려운 학생들에 대한 피드백과 의사소통이 어렵다는 점이다. 그러나 온라인 수업의 소통 방식이 교실과 다르다 하더라도 근본적으로 피드백이나 상호작용이 불가능한 것은 아니며 오히려 적절한 기술이 갖추어진다면, 개별화되고 차별화된 학습으로 효율적이면서도 효과적인 영어학습을 할 수 있고 여러 다양한 형태의 커뮤니케이션이 
가능할 수 있다(WEF, 2020)[6].

둘째, 온라인 영어 수업의 문제점으로 언급된 교사의 온라인 수업 역량 부족과 학교 인프라 부족, 취약계층 인프라 미비, 그리고 학습 지원의 어려움은 향후 지속적으로 관리, 개선되어야 하는 필수 영역이다. 본 연구에서 지적된 대부분의 문제점은 이 네 가지 영역의 준비 미흡과 연관이 있으며 이번 코로나 19 로 인한 온라인 수업의 전면 도입은 학교의 교육 정보화 수준과 학교 간, 교사 간, 학생 간 격차를 보여주었다. 따라서 온라인 수업의 개선 방안으로 다양한 원격수업을 가능하게 하는 통합 플랫폼 구축의 필요성을 제시함과 동시에 이를 통한 교수 학습 활동의 내용과 방법의 다양성과 확장성을 확보할 수 있어야 한다. 교사의 온라인 수업 역량 강화를 위해서는 장.단기적인 계획을 통해 모든 교사들에게 필수적으로 이수해야 하는 연수 프로그램이 설계되고 실행되어야 하겠다.

셋째, 미래 교육의 방향으로 본 연구에서는 온라인 초등영어 수업의 가장 효과적이면서도 효율적인 방안으로 개별학습의 가능성을 제시하였다. 지금까지 학교 교육은 집단 수업의 형태였으나 미래의 테크놀로지 활용 수업은 개별화와 맞춤화를 강조한다(한국교육학술정보원, 2016)[9]. 또한 교사들이 코로나 이후에도 온라인 수업에 대해 계속적인 활용에 대해 긍정적 의견을 제시하기 때문에 앞으로도 교실 수업 내에서 인공지능(AI)을 활용하는 자기주도적 신장 맞춤형 소프트웨어(온라인 도구)를 활용하거나 온,오프라인을 연계한 수업모델(블렌디드러닝, 플립러닝)등의 형태가 확장될 것이라고 전망한다. 따라서 온라인 수업의 특징을 살려 초등 영어교실 수업과 연계, 병행하는 형태가 가속화될 것이다.

본 연구는 지난 1 년간의 온라인 영어 수업과 인공지능 활용 영어 수업에 대한 교사의 경험과 인식에 대한 구체적인 현장의 목소리를 담아내는데 의의를 두고 있다. 그러나 연구 대상이 한정적이어서 연구 결과를 일반화하기에 한계를 가진다. 후속 연구를 통해 보다 체계적이고 표집 방식과 연구 대상의 확대, 학교 급수 등 변인에 원인이 되는 차이 분석이 추가로 연구될 필요가 있을 것이다.

\section{References}

[1] J. R. Kim, Web-based English education, Hankuk Moonwhasa, pp.26-42, (2001)

[2] H. J. Kim, An Analysis of Achievement and Teaching Presence in a blended learning environment: smart learning at an Online Universities, The Journal of Learner-Centered Curriculum and Instruction, (2018), Vol.18, No.8, pp.755-779, DOI: http://dx.doi.org/10.22251/jlcci.2018.18.8.755

[3] Y. W. Lee, A Study of Using Flipped Learning on Differentiated-level College Learners' Perceptions, Class Satisfaction, and Reading and English-speaking Achievement, The Journal of Learner-Centered Curriculum and Instruction, (2020), Vol.20, No.9, pp.181-206, DOI: http://dx.doi.org/10.22251/jlcci.2020.20.9.181.

[4] S. Hiltz, Evaluating the virtual classroom, Online Education: Perspectives on a New Environment, Praeger, pp.86-94, (1990)

[5] A. Romiszowski, R. Mason, Computer-mediated Communication, Handbook of Research for Educational Communications and Technology, 2nd Edition, Routledge, pp.397-432, (2004)

[6] Https://www.weforum.org/agenda/2020/04/coronavirus-education-global-covid19-online-digital-learning/, Apr 01 (2020)

[7] K. A. Heo, The development and validation of a digital Literacy scale for kindergarten teachers, Graduate school of Kyoungbuk University, Master's thesis, pp.9-12, (2011) 
[8] H. J. Kim, K. H. Na, The effect of middle School students'participation in a blended learning program on their English achievement, Secondary English Education, (2014), Vol.7, No.3, pp.49-74, UCI: G704-SER000010238.2014.7.3.004

[9] The direction of redesigning education in the technology era and various school models emerging, RM 2016-3, Korea Education and Research Information Service, pp.55-58, (2016) 